\title{
The Usefulness of C-Reactive Protein, Procalcitonin, and PELOD-2 Score as a Predictive Factor of Mortality in Sepsis
}

\author{
Munar Lubis*, Aridamuriany Dwiputri Lubis, Badai Buana Nasution \\ Department Department of Child Health, Faculty of Medicine, Universitas Sumatera Utara, Jl. Dr. Mansyur No.5, Medan 20155, Indonesia \\ *Corresponding author. E-mail: lubismunar@yahoo.com
}

Received date: Nov 28, 2019; Revised date: Feb 21, 2020; Accepted date: Mar 2, 2020

\section{Abstract}

$\mathrm{B}$

ACKGROUND: Sepsis in children is a significant cause of morbidity and mortality in the pediatric intensive care unit (PICU). Assessment of pediatric sepsis using serial Pediatric Logistic Organ Dysfunction (PELOD)-2 score can be used as a prognostic factor. The use of biomarkers of sepsis is also used for diagnosis and predicting outcomes. Many studies have suggested that C-reactive protein (CRP) and procalcitonin (PCT) can be used to predict mortality.

METHODS: A prospective cohort study was conducted to evaluate CRP, PCT, PELOD-2 score and its combination as a predictive factor of mortality in sepsis. All patients admitted to PICU Haji Adam Malik General Hospital, Medan, from April to November 2019 with suspected sepsis were included in this study. Blood examination and PELOD-2 scores were examined in the first 24 hours.
RESULTS: A total of 79 children were included with a mortality rate 55.7\%. The CRP, PCT, and PELOD-2 score were higher in nonsurvivor $(2.8(0.5-22.4) \mathrm{mg} / \mathrm{dL} ; 9.36$ (0.13-79.8) ng/mL; 9 (3-21), respectively). In multivariate logistic regression analysis, neither CRP nor PCT values could be independent predictors of mortality. The PELOD-2 score can be an independent predictor for mortality at a cut-off score of 7 (OR: 3.47 (95\% CI: 1.68-7.19)). The combination of PELOD-2 and CRP scores as predictors of mortality showed lower values than PELOD-2 and PCT scores $(0.80 v s$. 0.95$)$. The combination of all parameters only adds $1 \%$ of the predicted mortality value.

CONCLUSION: PELOD-2 score with PCT value are recommended to predict mortality children with sepsis.

KEYWORDS: sepsis, mortality, C-reactive protein, procalcitonin, PELOD-2 score

Indones Biomed J. 2020; 12(2): 102-8

\section{Introduction}

Sepsis in children remains an important problem in morbidity and mortality worldwide. The mortality rate in the Pediatric Intensive Care Unit (PICU) in developing countries can reach to $50 \%$.(1) According to the 2015 Sepsis Prevalence Outcomes and Therapies (SPROUT), causes of infections come from the respiratory system by $40 \%$, while the occurrence of organ dysfunction occurs in $67 \%$ of children with sepsis.(2) Previous study found that systemic inflammatory response syndrome (SIRS) occurred in $82 \%$ of PICU patients, of which $23 \%$ had sepsis, $4 \%$ severe sepsis, and 2\% septic shock.(3) In the PICU of Cipto Mangunkusumo Central General Hospital, Jakarta, the percentage of sepsis presentations was $19.3 \%$ with a mortality rate of $10 \%$.(4) A research at PICU of Haji Adam Malik General Hospital, Medan, showed the presentation of sepsis in boys was higher than girls with the most age was 1-50 months (76.5\%) and the mortality rate was $42 \%$.(5)

The new definition of sepsis was issued by The Society of Critical Care Medicine and The European Society of Intensive Care Medicine as life-threatening organ dysfunction.(6) Pathophysiological sepsis is a complex process between pathogens and the body's antibody system. In sepsis, there will be a dysregulation of 
responses from cytokines. The anti-inflammatory response will cause immunosuppression which increases the patient, thus worsening the patient's condition. This causes mitochondrial dysfunction induced by cellular hypoxia. Cell and tissue damage will result in damage-associated molecular patterns (DAMPs), which will cause myocardial dysfunction, multiple organ failure (MOF), and death.(7) Organ dysfunction in sepsis can be assessed using pediatric logistic organ dysfunction (PELOD)-2 score.(8)

Currently, the use of biomarkers in sepsis is used to support rapid diagnosis and prediction of outcomes.(9) The widely used biomarker is C-reactive protein (CRP), which response to inflammation better than infection.(10) Sepsis begins with an inflammatory reaction due to infection that causes tissue damage. The stimulation of organisms to pathogen-associated molecular patterns (PAMPs) or DAMPs will cause the release of proinflammatory cytokines. This process stimulate hepatocyte cells to secrete CRP.(11) CRP can be used as a prediction of mortality in children with sepsis.

Another biomarker used is procalcitonin (PCT). During inflammation, PCT is produced by two mechanisms, the direct pathway induced by lipopolysaccharides (LPS) or metabolic toxins from microbes, and the indirect pathways induced by inflammatory mediators such as interleukin (IL)-6, tumor necrosis factor (TNF)- $\alpha$. In sepsis due to bacteria, PCT is also produced through alternative routes. (12) Compared with CRP, PCT has a better diagnostic and prognostic value. PCT values increase as an inflammatory response caused by bacterial infection and several studies have suggested PCT as one of the promising markers in diagnosing sepsis and supporting antibiotic stewardship in systemic infections.(13)

Biomarkers in sepsis can be a supporting factor for diagnosis and therapeutic decision making. Early serum biomarkers can also be used to predict the prognosis in critically ill children.(10) Until now, there is no study before which compare the use of biomarkers such as CRP, PCT, PELOD-2 scores, or its combination in predicting the mortality of children with sepsis.

\section{Methods}

\section{Study Design}

This prospective cohort study was conducted in April to November 2019 in the PICU Haji Adam Malik General Hospital, Medan. Approval was taken from The Health Research Ethical Committee, Faculty of Medicine,
Universitas Sumatera Utara/Haji Adam Malik General Hospital (No. 303/TGL/KEPK FK USU-RSUP HAM/ 2019) and written consent was obtained from subject's parents. Eighty-four subjects with sepsis were included for the study with inclusion criteria of age $>28$ days to $<18$ years old, admitted to PICU. Pediatric surgical, trauma, or burn case was excluded.

\section{Method of Data Collection}

The following data was collected for the eligible enrolled subjects: age, gender, primary organ involvement, and nutritional status. The PELOD-2 score was used to assess the severity of illness and organ dysfunction. This score illustrates multiple organ failure related to mortality, so that it can be used as a score to determine the possibility of subject mortality at PICU. This score consists of 5 organ systems that can show the presence of multiple organ dysfunction in sepsis. CRP and PCT were measured at admission, prior to antibiotic within 24 hours of admission in PICU. All subjects' outcome were followed up, either died or moved to the ward.

\section{Statistical Analysis}

Continuous variables were presented as medians (minimummaximum). Categorical variables were expressed as frequencies (\%). Mann Whitney $\mathrm{U}$ test was used to assess the relationship between CRP, PCT, or PELOD-2 score with mortality. Multivariate logistic regression analysis was done to predict an outcome from a set of predictor variables in univariate analysis, with $p<0.05$ was considered statistically significant. The area under the receiver operator characteristic (ROC) was also used to assess the ability to predict the outcome. Statistical analysis was performed with SPSS version 22.0 program for Windows (IBM Corporation, New York, USA).

\section{Results}

Eighty-four subjects received therapy based on institutional protocol for sepsis. CRP or PCT examination was incomplete in 5 subjects, so only 79 subjects were included in the final analysis. There were 47 male $(59.5 \%)$ and 32 female $(40.5 \%)$ subjects with mostly $<1$ year old $(38 \%)$. The most indications treated at PICU were central nervous system disorders $(30.4 \%)$ due to meningitis, respiratory system disorders $(25.3 \%)$ due to bronchopneumonia, then shock $(20.3 \%)$, with the length of stay was 1 to 34 day. From this study, 44 subjects $(55.7 \%)$ died. Children 
with organ dysfunction in sepsis were described with clinical, laboratory parameters, blood culture, and organ dysfunction assessed by PELOD-2 scores. The PELOD-2 score in the lowest subjects was 2 and the highest was 21, with leukocytosis or leukopenia. The lowest CRP value in subjects was $0.5 \mathrm{mg} / \mathrm{dL}$ and the highest reached $22.4 \mathrm{mg} / \mathrm{dL}$. PCT values for all subjects were higher than normal values with the lowest value of $0.10 \mathrm{ng} / \mathrm{mL}$ to $79.8 \mathrm{ng} / \mathrm{mL}$. Bacterial growth was found in $51.9 \%$ blood, sputum, or urine culture. All characteristic data from the research sample can be seen in Table 1.

In children with sepsis, CRP, PCT, and PELOD-2 scores each had a significant association with mortality $(p<0.001)$. As a marker of infection, CRP and PCT values in sepsis children were higher in those who died $(2.8(0.5-$ 22.4); 9.36 (0.13-79.8), respectively). The PELOD-2 score as an organ dysfunction score in pediatric sepsis also showed a higher score in nonsurvivor (9 (3-21)) than survivor (6 (215)), $p<0.05$ (Table 2).

In this study, initial CRP and PCT had optimal cutoff points at $2.05 \mathrm{mg} / \mathrm{dL}$ and $5.4 \mathrm{ng} / \mathrm{mL}$. In the univariate analysis, initial CRP values were higher in non-survival patients (OR: $1.79(95 \% \mathrm{CI}: 1.15-2.78)$ ) and same with initial PCT value (OR: 10.87 (95\% CI: 3.67-32.17)). However, in multivariate regression analysis, neither CRP nor PCT values could be independent predictors of mortality. Only

Table 1. Basic characteristics of study participants at baseline.

\begin{tabular}{|c|c|}
\hline Indicator & $\mathrm{n}=79$ \\
\hline \multicolumn{2}{|l|}{ Age, n $(\%)$} \\
\hline$<1$ years old & $30(38)$ \\
\hline $1-<5$ years old & $13(16.5)$ \\
\hline $5-<10$ years old & $10(12.7)$ \\
\hline $10-<18$ years old & $26(32.9)$ \\
\hline \multicolumn{2}{|l|}{ Gender, n (\%) } \\
\hline Male & $47(59.5)$ \\
\hline Female & $32(40.5)$ \\
\hline Body weight (kg), median (min-max) & $12(2.8-80)$ \\
\hline Body height (cm), median (min-max) & $96(45-166)$ \\
\hline \multicolumn{2}{|l|}{ Nutritional status, $\mathrm{n}(\%)$} \\
\hline Severe malnutrition & $17(21.5)$ \\
\hline Mild-moderate malnutrition & $17(21.5)$ \\
\hline Well-nourished & $39(49.4)$ \\
\hline Overweight & $6(7.6)$ \\
\hline \multicolumn{2}{|l|}{ ICU indication, n (\%) } \\
\hline Respiratory disorder & $20(25.3)$ \\
\hline Cardiovascular disorder & $4(5.1)$ \\
\hline Neurological disorder & $24(30.4)$ \\
\hline Circulation disorder & $16(20.3)$ \\
\hline Nephrology disorder & $15(19.0)$ \\
\hline \multicolumn{2}{|l|}{ Outcome, n(\%) } \\
\hline Survival & $35(44.3)$ \\
\hline Death & $44(55.7)$ \\
\hline Leucocyte count $(/ \mu \mathrm{L})$, median (min-max) & $14,900(2,470-62,500)$ \\
\hline Blood lactate (U/L), median (min-max) & $1.9(0.7-39)$ \\
\hline CRP (mg/dL), median (min-max) & $2.1(0.5-22.4)$ \\
\hline PCT (ng/mL), median (min-max) & $6.1(0.10-79.8)$ \\
\hline PELOD-2 score, median (min-max) & $8(2-21)$ \\
\hline \multicolumn{2}{|l|}{ Culture result, n(\%) } \\
\hline Positive & $41(51.9)$ \\
\hline Negative & $38(48.1)$ \\
\hline
\end{tabular}


Table 2. Association CRP, PCT, and PELOD-2 score with mortality.

\begin{tabular}{lccc}
\hline \multirow{2}{*}{ Parameter } & \multicolumn{2}{c}{ Median (min-max) } & p-value* \\
\cline { 2 - 3 } & Non-survivor & Survivor & \\
\hline CRP $(\mathrm{mg} / \mathrm{dL})$ & $2.8(0.5-22.4)$ & $1.2(0.5-5.3)$ & $<0.001$ \\
PCT $(\mathrm{ng} / \mathrm{mL})$ & $9.36(0.13-79.8)$ & $1.57(0.10-25.0)$ & $<0.001$ \\
PELOD-2 score & $9(3-21)$ & $6(2-15)$ & $<0.001$ \\
\hline
\end{tabular}

*Analyzed with Mann-Whitney test.

the PELOD-2 score could be an independent predictor for mortality at a cut-off point of 7 with an OR of 3.47 (95\% CI: 1.68-7.19) (Table 3).

The PELOD-2 scores gave a moderate strength area under the receiver operating characteristic (ROC) curve (AUC) values as predictors of mortality (AUC: 0.75 ). The addition of biomarkers increases the predictor value where the PELOD-2 score and CRP were lower than assessing the PELOD-2 score and PCT (AUC: 0.80 vs. 0.95). All assessments of PELOD-2 score, CRP and PCT only add $1 \%$ compared to the PELOD-2 score and PCT, so adding CRP did not give a significant value. In this study, PELOD-2 scores combination with PCT were recommended for predicting mortality in children with sepsis (Table 4, Figure 1).

\section{Discussion}

Sepsis still become the cause of death in children in the last two decades, especially in developing countries. Study in China obtained a mortality rate of $34.6 \%$ in sepsis and severe sepsis of children, two-thirds of deaths occurred within 72 hours of treatment.(14) Another study in Columbia described there were $50 \%$ of pediatric patients treated in PICU with shock sepsis and $40 \%$ experienced multiple organ dysfunction syndrome, with a mortality rate of $34 \%$. (15) A large-scale study in 2015 found that the mortality rate due to sepsis in children worldwide was $25 \%$.(2) In this study, the mortality rate was $55.7 \%$, where the most indication of PICU was central nervous system disorders.

In the pediatric population, PELOD-2 scores are used to assess organ dysfunction. The PELOD-2 scores serials are related to prognostic of death.(16) In this study, PELOD-2 scores in patients with sepsis at PICU were higher in nonsurvivor than survivor patients $(9$ (3-21)) vs. 6 (2-15), respectively). Multivariate analysis of this study showed the PELOD-2 score could be an independent predictor for mortality in children with sepsis with cut-off point score 7. However, the AUC did not show strong strength value (AUC: 0.75), so that it was better combined with biomarker examination.

The use of biomarkers in pediatric sepsis can indicate the severity of sepsis. In addition, biomarkers are used to assess prognosis, guidelines for administering antibiotic therapy, evaluation of therapeutic response, or prediction of complications and organ dysfunction in sepsis.(17) Biomarker examinations for infections such as CRP and PCT are often performed before starting antibiotic treatment. This study compared PELOD-2 scores and its combination with CRP, PCT, or both in predicting mortality.

$\mathrm{CRP}$ is an inflammatory cytokine. Existing studies assess CRP as a marker of diagnosis infection and prognosis in sepsis. Other study in critically ill adults showed serial CRP could be a good predictor of prognosis compared to other biomarkers. It was also used to assess therapeutic

Table 3. Univariate and multivariate analysis for CRP, PCT, PELOD-2 score as predictive factor of mortality in sepsis.

\begin{tabular}{lccc}
\hline \multirow{2}{*}{\multicolumn{1}{c}{ Parameter }} & \multicolumn{2}{c}{ OR $(95 \%$ CI) } & P-value** \\
\cline { 2 - 3 } & \multicolumn{1}{c}{ Univariate } & Multivariate & \\
\hline CRP $(\mathrm{mg} / \mathrm{dL})$ & $1.79(1.15-2.78)$ & & \\
PCT $(\mathrm{ng} / \mathrm{mL})$ & $10.87(3.67-32.17)$ & & \\
PELOD-2 score & $3.47(1.68-7.19)$ & $8.39(1.22-57.88)$ & $<0.05$ \\
\hline
\end{tabular}

**Analyzed with logistic regression analysis. OR: odds ratio; CI: confidence interval. 
Table 4. AUC predictor mortality in children with sepsis.

\begin{tabular}{lcc}
\hline \multicolumn{1}{c}{ Parameter } & AUC & $\boldsymbol{p}$-value** \\
\hline PELOD-2 score & $0.75(0.64-0.86)$ & $<0.001$ \\
PELOD-2 score and CRP & $0.80(0.70-0.90)$ & $<0.001$ \\
PELOD 2 score and PCT & $0.95(0.90-1.0)$ & $<0.001$ \\
PELOD 2 score and CRP and PCT & $0.96(0.93-1.0)$ & $<0.001$ \\
\hline
\end{tabular}

**Analyzed with logistic regression analysis. AUC: area under the ROC curve.

response.(18) In this study, there was a relationship between CRP values and mortality, where CRP was higher in nonsurvivor compared to survivor patients $(2.8(0.5-22.4)$ vs. 1.2 (0.5-5.3), $p<0.001)$. However, CRP alone could not be an independent predictor of mortality in this study. Similar to another study of 172 children, a cut-off $7.1 \mathrm{mg} / \mathrm{dL}$ CRP was associated with organ dysfunction and mortality in hospitalized children. A combination with ferritin increased the predicted mortality value by more than $20 \%$ compared to CRP assessment alone. Increased CRP value alone (not above the cut-off point) was not related to mortality in the study.(19) In accordance with the results of the CRP examination in this study, the cut-off point of $1.2 \mathrm{mg} / \mathrm{dL}$ was lower compared to the results from previous studies.

PCT is not released into circulation under normal circumstances. Several studies had assessed PCT as a diagnostic and predictive factor for outcomes in sepsis patients. PCT has a higher prognostic value for bacterial infection and mortality more than other markers of SIRS such as temperature, tachycardia, tachypnea, and elevated leukocytes.(20) Research on 175 children with sepsis shock showed the initial PCT value was higher in children with multiple organ failure and mortality.(21) A study in children with sepsis at PICU showed high PCT values in non-survivor. The results of the ROC curve and the AUC value showed a result of 0.83 (95\% CI $0.77-0.88)$ with a cut-off of $47 \mathrm{ng} /$ mL.(22) Similar to this study, the median PCT was high in patients who were died compared to living (9.36 (0.13-79.8) vs. $1.57(0.10-25), p<0.001)$. However, like CRP, the initial PCT value was not significant as an independent predictor in multivariate analysis. In children, there is no single biomarker that is claimed to be a good predictor of outcome. Complex interactions between immune responses and gene variations cause wide differences in examination results, so a combination of assessment variables is recommended. $(23,24)$ Multicenter studies in sepsis patients in Korea also showed that CRP and PCT values respectively could not be independent predictors in multivariate logistic regression

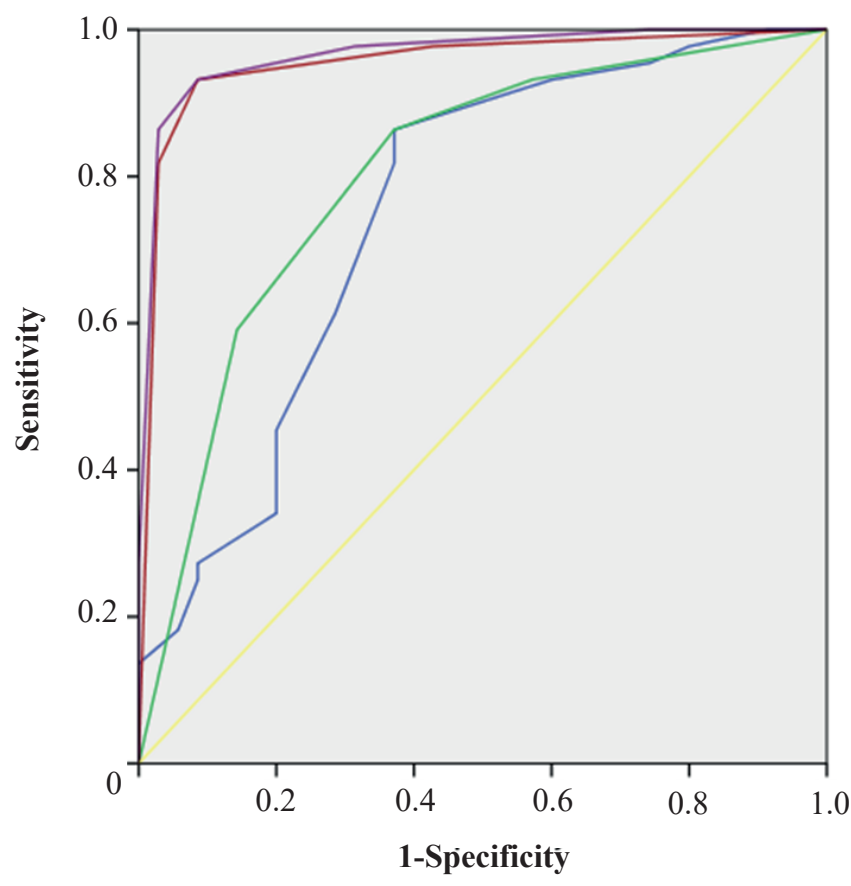

Figure 1. ROC curve of CRP, PCT, and PELOD-2 score as a predictor of mortality in children with sepsis. 
tests for mortality.(25) A prospective cohort study in India showed no significant association between CRP and PCT with mortality ( $p=0.839, p=0.346$, sequential).(9)

In this study, the PELOD score -2 could be an independent predictor of mortality. The addition of PCT would increase the predictor strength to AUC 0.95. While the addition of CRP to PELOD-2 increased the predictor of mortality to AUC 0.80. Multivariate analysis of all parameters did not significantly increase the strength of the AUC compared to the assessment of the PELOD-2 score combination with PCT. The PELOD-2 scores combination with PCT were recommended to be a predictor of mortality in children with sepsis.

There are some limitations in this study. First, the subjects were only children treated in PICU with sepsis, no control subjects were included in this study. Second, this study only analyzed initial biomarkers and PELOD-2 scores, with no serial evaluation. This is a single center study so the cut-off values and recommendations obtained cannot be generalized.

\section{Conclusion}

Assessment of pediatric sepsis with PELOD-2 scores can be an independent prognostic factor with a cut-off point of 7 at the study center. The PELOD-2 score combined with the value of PCT was recommended to be a predictive factor of mortality. Further large scale multicenter research studies are needed to assess CRP, PCT, and PELOD-2 scores for early prognostication in children with sepsis.

\section{Acknowledgements}

We thanked all participant that taking part in this study. The authors disclosed receipt of the following financial support for the research provided by TALENTA USU 2019 no.4167/ UN5.1.R/PPM/2019 .

\section{References}

1. Khan MR, Maheshwari PK, Masood K, Qamar FN, Haque AU. Epidemiology and outcome of sepsis in a tertiary care PICU of Pakistan. Indian J Pediatr. 2012; 79: 1454-8.

2. Weiss SL, Fitzgerald JC, Maffei FA. Discordant identification of pediatric severe sepsis by research and clinical definition in the SPROUT international point prevalence study. Crit Care. 2015; 19: 325-34.
3. Proulx F, Fayon M, Farell CA, Lacroix J, Guthier M. Epidemiology of sepsis and multiple organ dysfunction syndrome in children. CHEST. 2006; 109: 1033-7.

4. Saraswati DD, Pudjiadi AH, Djer MM, Supriyatno B, Syarif DR, Kurniati N. Faktor risiko yang berperan pada mortalitas sepsis. Sari Pediatri. 2014; 15: 281-8.

5. Salim E, Lubis M, Ali M. Hubungan antara Nilai troponin $T$ dan mortalitas pada anak syok sepsis yang dirawat di PICU [Thesis]. Medan: Universitas Sumatera Utara; 2014.

6. Singer M, Deutchman CS, Seymour CW, Shankar-Hari M, Annane D, Baurer $\mathrm{M}$, et al. The third international consensus definitions for sepsis and septic shock (Sepsis-3). JAMA. 2016; 315: 801-10.

7. Chun K, Syndergaard C, Damas C, Trubey R, Mukindaraj A, Qian S, et al. Sepsis pathogen identification. J Lab Automation. 2015; 20 : 539-61.

8. Leteurtre S, Duhamel A, Deken V, Lacroix J, Leclerc F. Daily estimation of the severity organ dysfunctions in critically ill children by using the PELOD-2 score. Crit Care. 2015; 19: 324. doi: 10.1186/s13054-015-1054-y.

9. Sharma D, Farahbakhsh N, Shastri S, Sharma P. Biomarkers for diagnosis of neonatal sepsis: a literature review. J Matern Fetal Neonatal Med. 2018; 31: 1646-59.

10. Siddiqui I, Jafri L, Abbas Q, Raheem A, Haque AU. Serum procalcitonin, C-reactive protein and lactic acid to organ failure and outcome in critically ill pediatric population. Indian J Crit Care Med. 2018; 22: 91-5.

11. Faix JD. Biomarkers of sepsis. Crit Rev Clin Lab Sci. 2013; 50: 23 36.

12. Vijayan AL, Vanimaya, Ravindran S, Saikant R, Lakshmi S, Kartik $\mathrm{R}$, et al. Procacitonin: a promising diagnostic marker for sepsis and antibiotic therapy. J Intensive Care. 2017; 5: 51. doi: 10.1186/ s40560-017-0246-8.

13. Lanziotti VS, Povoa P, Soares M, Silva JRL, Barbosa AP, Salluh JIF. Use of biomarkers in pediatric sepsis: literature review. Rev Bras Ter Intensiva. 2016; 28: 462-82.

14. Wang Y, Sun B, Yue H, Li B, Yang X, Shan C, et al. An epidemiologic survey of pediatric sepsis in regional hospitals in China. Pediatr Crit Care Med. 2014; 15: 814-20.

15. Jaramillo-Bustamante JC, Marin-Agudelo A, Fernandez-Laverde M, Bareno-silva J. Epidemiology of sepsis in pediatric intensive care units: first Columbian multicentre study. Pediatr Crit Care Med. 2012; 13: 501-8.

16. Karam O, Demaret P, Duhamel A, Shefler A, Spinella PC, Stanworth $\mathrm{SJ}$, et al. Performance of the Pediatric Logistic Organ Dysfunction-2 score in critically ill children requiring plasma transfusions. Ann Intensive Care. 2016; 6: 98. doi: 10.1186/s13613-016-0197-6.

17. Marshall JC, Reinhart K. Biomarkers of sepsis. Crit Care Med. 2009; 37: 2290-8

18. Coelho LM, Salluh JI, Soares M, Bozza FA, Verdeal JC, Castro-FariaNeto HC. Patterns of c-reactive protein ratio response in severe community-acquired pneumonia: a cohort study. Crit Care. 2012; 16: R53. doi: 10.1186/cc11291.

19. Horvat CM, Bell J, Kantawala S, Au AK, Clark RS, Carcillo JA. C-reactive protein and ferritin are associated with organ dysfunction and mortality in hospitalized children. Clin Pediatr. 2019; 58: 75260 .

20. Memar MY, Varshochi M, Shokouhi B, Asgharzadeh M, Kafil HS Procalcitonin: the marker of pediatric bacterial infection. Biomed Pharmacother. 2017; 96: 936-43.

21. Hatherill M, Tibby SM, Turner C, Ratnavel N, Murdoch IA Procalcitonin and cytokine levels: relationship to organ failure and mortality in pediatric septic shock. Crit Care Med. 2000;28;2591-4. 
22. Wu Q, Nie J, Wu F, Xou X, Chen F. Prognostic value of highsensitivity C-Reactive Protein, procalcitonin, and pancreatic stone protein in pediatric sepsis. Med Sci Monit. 2017; 23: 1533-9.

23. Nakamura M, Kono R, Nomura S, Utsunomiya H. Procalcitonin; mysterious protein in sepsis. J Basic Clinical Med. 2013; 2: 7-11.

24. Vijayan AL, Ravindran S, Saikant R, Lakshmi S, Kartik R, Manoj G. Procacitonin: a promising diagnostic marker for sepsis and antibiotic therapy. J Intensive Care. 2017; 5: 51. doi: 10.1186/ s40560-017-0246-8.

25. Ryoo SM, Han KS, Shin TG, Hwang SY, Chung SP, Hwang YJ. The usefulness of C-Reactive Protein and procalcitonin to predict prognosis in septic shock patients: a multicenter prospective registry-based observational study. Scientific Reports. 2019; 9: 6579. doi: 10.1038/s41598-019-42972-7. 